\title{
Targeted and Reduction-Sensitive Crosslinked PLGA Nanotherapeutics for Safer and Enhanced Chemotherapy of Malignant Melanoma
}

\author{
Xiuxiu Wang, Min Qiu, Chao Deng, Ru Cheng* and Zhiyuan Zhong*
}

Biomedical Polymers Laboratory, and Jiangsu Key Laboratory of Advanced Functional Polymer Design and Application, College of Chemistry, Chemical Engineering and Materials

Science, and State Key Laboratory of Radiation Medicine and Protection, Soochow University, Suzhou 215123, PR China

* Corresponding authors. Tel/Fax: +86-512-65880098, E-mail: rcheng@ suda.edu.cn (R. Cheng); zyzhong@suda.edu.cn (Z.Zhong)

\section{Materials}

Maleimide-functionalized poly(ethylene glycol) (MAL-PEG-OH, $M_{\mathrm{n}}=5.0 \mathrm{~kg} / \mathrm{mol}$, Creative PEG Works), cRGDfC (98\%, GL Biochem Ltd.), hydroxyl terminated star poly(lactide-co-glycolide) (sPLGA, LA/GA $\left.=50 / 50 \quad(\mathrm{~mol} . / \mathrm{mol}),. M_{\mathrm{n}}=15.0 \mathrm{~kg} / \mathrm{mol}\right)$, 1,4-dithiothreitol (DTT, 99\%, Merck), glutathione (GSH, $99 \%$, Roche), 3-(4,5-dimethylthiazol-2-yl)-2,5-di-phenyltetrazolium bromide (MTT, Sigma), 4',6-diamidino-2-phenylindole (DAPI, Invitrogen), BCA Protein Assay Kit (Thermo Scientific), stannous octoate $\left(\operatorname{Sn}(\mathrm{Oct})_{2}, \geq 92.5 \%\right.$, Sigma-Aldrich) and trypsin (Jinuo Biomedical Technology) were used as received. DOX was obtained by treating doxorubicin hydrochloride (DOX.HCl, $99 \%$, Beijing Zhongshuo Pharmaceutical Technology Development Co., Ltd) with excess triethylamine in DMSO. sPLGA-LA was synthesized as previously reported. ${ }^{1}$ Methoxy poly(ethylene glycol) $\left(\mathrm{mPEG}-\mathrm{OH}, M_{\mathrm{n}}=5.0 \mathrm{~kg} / \mathrm{mol}\right.$, Fluka) was dried by azeotropic distillation from anhydrous toluene before use. D,L-Lactide (99\%, $\mathrm{J} \& \mathrm{~K})$ was purified by recrystallization in anhydrous ethyl acetate. Dichloromethane (DCM) was dried using a PS-MD-4 PureSolv solvent purification system (Innovative Technology, 
USA). The other solvents were used as received. Pegylated liposomal doxorubicin (Lipo-Dox, LIBOD) was obtained from Shanghai Fudan-Zhangjiang Bio-Pharmaceutical Co., Ltd. cRGD-PEG-PDLLA and PEG-PDLLA copolymers were synthesized in our lab.

\section{Characterizations}

${ }^{1} \mathrm{H}$ NMR spectra were recorded on a Unity Inova 400 spectrometer operating at 600 $\mathrm{MHz}$ using $\mathrm{CDCl}_{3}$ or DMSO as a solvent. The molecular weight and polydispersity index (PDI) of copolymers were determined by a Waters 1515 gel permeation chromatograph instrument equipped with MZ-gel SD plus columns (500 $\mathrm{A}, 10 \mathrm{E} 3 \AA$, 10E4 $\AA$ ) following a differential refractive-index detector (RID 2414). DMF containing 0.05 M LiBr was used as the mobile phase at a flow rate of $0.8 \mathrm{~mL} / \mathrm{min}$ through the columns at $40{ }^{\circ} \mathrm{C}$. A series of narrow PMMA standards were used for molecular weight calibration. The hydrodynamic size of nanoparticles was determined at $25{ }^{\circ} \mathrm{C}$ using dynamic light scattering (DLS, Zetasizer Nano-ZS, Malvern Instruments) equipped with a $633 \mathrm{~nm}$ He-Ne laser using back-scattering detection. The measurements were performed in triplicate. Transmission electron microscopy (TEM) was performed using a Tecnai G220 TEM operated at an accelerating voltage of 120 $\mathrm{kV}$. The samples were prepared by dropping $10 \mu \mathrm{L}$ of $0.25 \mathrm{mg} / \mathrm{mL}$ nanoparticles suspension on the copper grid followed by staining with $1 \mathrm{wt} . \%$ phosphotungstic acid. The amount of DOX was determined by fluorometry (Agilent Technologies, USA). Flow cytometry was conducted on a flow cytometer (FACS Calibur, BD Biosciences, USA). The fluorescence images of cells were taken on a confocal laser scanning microscope (CLSM, LeicaTCSSP5, Wetzlar, Germany). For MTT assays, the absorbance at a wavelength of $490 \mathrm{~nm}$ was measured using a microplate reader (Thermo Multiskan FC).

\section{Synthesis of cRGD-PEG-PDLLA and PEG-PDLLA diblock copolymers}

cRGD-PEG-PDLLA polymer was synthesized via the Michael addition of maleimide functionalized PEG-PDLLA copolymer (MAL-PEG-PDLLA) with cRGDfC (cRGD-SH). Firstly, MAL-PEG-PDLLA was synthesized by the ring-opening polymerization of $\mathrm{D}$, L-lactide using MAL-PEG-OH as an initiator and stannous octoate $\left(\operatorname{Sn}(\mathrm{Oct})_{2}\right)$ as a catalyst. Typically, under a nitrogen atmosphere, into stirred solution of MAL-PEG-OH $\left(M_{\mathrm{n}}=5.0\right.$ $\mathrm{kg} / \mathrm{mol}, 0.5 \mathrm{~g}, 0.1 \mathrm{mmol})$ and D,L-lactide $(0.4 \mathrm{~g}, 2.8 \mathrm{mmol})$ in anhydrous toluene $(2.5 \mathrm{~mL})$ was quickly added $0.5 \mathrm{~mL}$ of $\mathrm{Sn}(\mathrm{Oct})_{2}$ stock solution $(0.2 \mathrm{~mol} / \mathrm{L})$ in toluene. The reaction vessel was sealed and placed in an oil-bath thermostat at $110{ }^{\circ} \mathrm{C}$. After $48 \mathrm{~h}$, the reaction was terminated by adding acetic acid. MAL-PEG-PDLLA copolymer was isolated by precipitation 
in cold ethyl ether, filtration and drying under vacuum for $48 \mathrm{~h}$. Yield: $90.3 \%$. ${ }^{1} \mathrm{H}$ NMR (600 $\mathrm{MHz}, \mathrm{CDCl}_{3}$, Fig. S1): $\delta 6.7$ (-CHCON-), $\delta 5.16\left(-\mathrm{CH}\left(\mathrm{CH}_{3}\right) \mathrm{O}-\right), 3.65\left(-\mathrm{CH}_{2} \mathrm{CH}_{2} \mathrm{O}-\right), 1.56$ $\left(-\mathrm{CH}\left(\mathrm{CH}_{3}\right) \mathrm{O}-\right) \cdot M_{\mathrm{n}}\left({ }^{1} \mathrm{H} \mathrm{NMR}\right)=8.8 \mathrm{~kg} / \mathrm{mol} \cdot M_{\mathrm{n}}(\mathrm{GPC})=13.9 \mathrm{~kg} / \mathrm{mol} . M_{\mathrm{w}} / M_{\mathrm{n}}(\mathrm{GPC})=1.2$.

cRGD-PEG-PDLLA polymer was obtained by the Michael addition of MAL-PEG-PDLLA and cRGD-SH in DMF. The reaction was carried out at $30{ }^{\circ} \mathrm{C}$ for $24 \mathrm{~h}$. The final product, cRGD-PEG-PDLLA, was isolated through dialysis against deionized water for $48 \mathrm{~h}$ (MWCO $7000 \mathrm{Da}$ ) followed by lyophilization. Yield: 85.4\%. ${ }^{1} \mathrm{H}$ NMR (600 MHz, DMSO- $d_{6}$, Fig. S2): $\delta 7.19$ and 7.21 (cRGD), $5.16\left(-\mathrm{CH}\left(\mathrm{CH}_{3}\right) \mathrm{O}-\right), 3.65\left(-\mathrm{CH}_{2} \mathrm{CH}_{2} \mathrm{O}-\right), 1.56$ $\left(-\mathrm{CH}\left(\mathrm{CH}_{3}\right) \mathrm{O}-\right) \cdot M_{\mathrm{n}}\left({ }^{1} \mathrm{H} \mathrm{NMR}\right)=8.8 \mathrm{~kg} / \mathrm{mol} . M_{\mathrm{n}}(\mathrm{GPC})=14.5 \mathrm{~kg} / \mathrm{mol} . M_{\mathrm{w}} / M_{\mathrm{n}}(\mathrm{GPC})=1.2$. The graft efficiency of cRGD determined by BCA protein assay kit was $96.7 \%$. mPEG-PDLLA polymer was synthesized using similar method as for MAL-PEG-PDLLA polymer, except using mPEG-OH as an initiator.

\section{DLC and DLE determination}

To determine the drug loading content (DLC) and drug loading efficiency (DLE), suspensions of DOX-loaded nanoparticles (DOX-cRGD-sPLGA XNPs) were freeze-dried, dissolved in DMSO and analyzed with fluorescence spectroscopy (Ex. $480 \mathrm{~nm}$ and Em. 560 $\mathrm{nm})$. A calibration curve was obtained with DOX/DMSO solutions with different DOX concentrations. DLC and DLE were calculated according to the following formulae:

DLC $(w t . \%)=($ weight of loaded drug/total weight of loaded drug and polymer $) \times 100$ $\operatorname{DLE}(\%)=($ weight of loaded drug/weight of drug in feed $) \times 100$

\section{Size change under dilution, 10\% FBS and $10 \mathrm{mM}$ GSH measured by DLS}

The stability of cRGD-sPLGA XNPs against 10\% FBS or extensive dilution was assessed by monitoring the size changes of the nanoparticles via DLS. Samples were maintained at $37{ }^{\circ} \mathrm{C}$ in a shaking bath (THZ-C, Taicang Instrument Factory, Jiangsu, China) at $200 \mathrm{rpm}$ for $24 \mathrm{~h}$. At desired time intervals, the sizes were determined by DLS.

The destabilization of cRGD-sPLGA XNPs in response to10 mM GSH was investigated in PB buffer (10 mM, pH 7.4) by DLS. Briefly, cRGD-sPLGA XNPs dispersion and GSH solution were gently bubbled with nitrogen gas for $10 \mathrm{~min}$, respectively. Then GSH solution was quickly added into the nanoparticles dispersion (final GSH concentration: $10 \mathrm{mM}$ ) and the mixture was immediately placed in a shaking bath $(200 \mathrm{rpm})$ at $37{ }^{\circ} \mathrm{C}$. At different time intervals, the size of nanoparticles was measured using DLS. 


\section{In vitro $\mathrm{DOX}$ release}

In vitro release of DOX from DOX-cRGD-sPLGA XNPs was studied using a dialysis tube (Spectra/Pore, MWCO 12000) at $37{ }^{\circ} \mathrm{C}$ in PB (10 mM, pH 7.4) in the presence or absence of $10 \mathrm{mM} \mathrm{GSH}$. To acquire sink conditions, drug release studies were performed at a nanoparticles concentration of $0.1 \mathrm{mg} / \mathrm{mL}$ (DOX concentration: $20 \mu \mathrm{g} / \mathrm{mL}$ ) with $0.5 \mathrm{~mL}$ of nanoparticles dispersion dialyzed against $25 \mathrm{~mL}$ of the same media. At desired time intervals, $5 \mathrm{~mL}$ of release medium was taken out and replenished with an equal volume of fresh medium. The amount of DOX released was determined by using fluorescence measurements.

\section{Cell culture and animal models}

Highly metastatic B16F10 murine melanoma cells and MCF-7 human breast cells were obtained from the Type Culture Collection of the Chinese Academy of Sciences, Shanghai, China. B16F10 cells were maintained in MEM medium (HyClone, Logan, Utah, USA) supplemented with $1 \%$ (v/v) penicillin, streptomycin (Jinuo Biomedical Technology, Hangzhou, Zhejiang, China) and 10\% (v/v) fetal bovine serum (FBS, Gibco, Invitrogen, USA). MCF-7 cells were maintained in DMEM medium (HyClone, Logan, Utah, USA) with the same supplements as for culturing B16F10 cells. The cells were cultured as a monolayer in a humidified atmosphere containing $5 \% \mathrm{CO}_{2}$ at $37^{\circ} \mathrm{C}$.

Female C57BL/6 mice of 4-6 weeks age were purchased from Shanghai SLAC laboratory animal Co., Ltd. (Shanghai, China). All animal experiments were approved by the Animal Care and Use Committee of Soochow University of Laboratory Animals. B16F10 melanoma bearing mice model was established by subcutaneously injecting $2 \times 10^{6}$ B16F10 cells in $50 \mu \mathrm{L}$ of PBS in the hind flank of C57BL/6 mice. When the tumor sizes reached around $100-120 \mathrm{~mm}^{3}$ and $50-70 \mathrm{~mm}^{3}$, the mice were weighted and randomly divided into different groups for biodistribution and in vivo treatment studies, respectively.

\section{MTT assays}

The cytotoxicity of blank nanoparticles and the antitumor activity of DOX-loaded nanoparticles were determined by the MTT assays. Briefly, B16F10 cells were seeded at a density of $3 \times 10^{3}$ cells/well in 96-well plates and cultured at $37{ }^{\circ} \mathrm{C}$ with $5 \% \mathrm{CO}_{2}$ for $24 \mathrm{~h}$. The prescribed amounts of DOX-loaded nanoparticles or blank nanoparticles in $10 \mu \mathrm{L}$ of PBS was added. For antitumor activity studies, the cells were incubated with different DOX-loaded nanoparticles for $4 \mathrm{~h}$, the medium was removed and replaced with fresh medium, and the cells 
were further cultured for another $44 \mathrm{~h}$. For evaluating the cytotoxicity of blank nanoparticles, the cells were incubated with nanoparticles for $48 \mathrm{~h}$. Subsequently, $20 \mu \mathrm{L}$ of MTT stock solution $(5 \mathrm{mg} / \mathrm{mL})$ was added to each well, and the plates were further incubated for $4 \mathrm{~h}$ at $37^{\circ} \mathrm{C}$ in the dark. The medium was discarded and $150 \mu \mathrm{L}$ of DMSO was added to dissolve the MTT-formazan generated by live cells. Cell viability was assessed by the absorbance at 490 $\mathrm{nm}$ of the DMSO solution measured on a microplate reader. The data were expressed as the percentages of viable cells compared to those of untreated cells.

\section{In vivo pharmacokinetics}

The DOX level in blood was measured by withdrawing $\sim 50 \mu \mathrm{L}$ of blood from retro-orbital sinus of Balb/c mice at different time points post-injection of DOX-cRGD-sPLGA XNP (10 mg DOX equiv./kg). Each blood sample was dissolved in 0.15 $\mathrm{mL}$ of lysis buffer (1\% v/v Triton X-100) with brief sonication. DOX was extracted by incubating blood samples in hydrochloric acid-isopropanol (HCl-IPA) at $-20{ }^{\circ} \mathrm{C}$ overnight. The samples were vortexed and centrifuged at 20,000 rpm for $15 \mathrm{~min}$. The DOX level of the supernatant was determined by fluorescence measurement. The elimination half-life time $\left(\mathrm{t}_{1 / 2}\right.$, $\beta$ ) was calculated by fitting the experimental data using Software Origin 8 exponential decay 2 model: $\mathrm{y}=\mathrm{A}_{1} \times \exp \left(-\mathrm{x} / \mathrm{t}_{1}\right)+\mathrm{A}_{2} \times \exp \left(-\mathrm{x} / \mathrm{t}_{2}\right)+\mathrm{y}_{0}$, and taking $\mathrm{t}_{1 / 2, \alpha}=0.693 \times \mathrm{t}_{1}$, and $\mathrm{t}_{1 / 2, \beta}=$ $0.693 \times \mathrm{t}_{2}$.

\section{Biodistribution}

DOX-cRGD-sPLGA XNPs, DOX-sPLGA XNPs or Lipo-DOX (10 mg DOX equiv./kg) were $i . v$. injected into B16F10 melanoma bearing C57BL/6 mice. After $6 \mathrm{~h}$, tumors and main organs (heart, liver, spleen, lung, and kidney) were excised, washed, weighed, and homogenized in $0.6 \mathrm{~mL}$ of $1 \%$ Triton $\mathrm{X}-100$. Then, $0.9 \mathrm{~mL}$ of the extraction solution (HCl-IPA) was added, and the samples were incubated at $-20{ }^{\circ} \mathrm{C}$ overnight. After vortexing and centrifugation $(17,226 \times \mathrm{g}, 15 \mathrm{~min})$, the DOX concentration of the supernatant was determined by fluorescence measurement and presented as the percentage of injected dose per gram tissue $(\% \mathrm{ID} / \mathrm{g})$.

\section{Statistical analyses}

Data are presented as the mean \pm standard deviation. Difference between groups was analyzed using the one way analysis of variance (ANOVA). Survival results were analyzed by 
the Kaplan-Meier technique using Graphpad Prism software. A log-rank test for comparisons was used. $* p<0.05$ was considered significant, and $*^{*} p<0.01, * * * p<0.001$ were considered highly significant.

Table S1 Characterization of MAL-PEG-PDLLA and cRGD-PEG-PDLLA copolymers.

\begin{tabular}{cccc}
\hline & & \multicolumn{2}{c}{$\mathrm{GPC}^{\mathrm{b}}$} \\
\cline { 3 - 4 } Polymer & ${ }^{1} \mathrm{H} \mathrm{NMR}^{\mathrm{a}}$ & $M_{\mathrm{n}}(\mathrm{kg} / \mathrm{mol})$ & $M_{\mathrm{w}} / M_{\mathrm{n}}$ \\
\hline MAL-PEG-PDLLA & $5.0-3.8$ & 13.9 & 1.2 \\
cRGD-PEG-PDLLA & $5.0-3.8$ & 14.5 & 1.2 \\
\hline
\end{tabular}

${ }^{a}$ Determined by ${ }^{1} \mathrm{H}$ NMR end-group analysis;

${ }^{\mathrm{b}}$ Determined by GPC measurements using DMF as an eluent at a flow rate of $0.8 \mathrm{~mL} / \mathrm{min}$ (standards: PMMA, $25^{\circ} \mathrm{C}$ ).<smiles>O=C(CCN1C(=O)C=CC1=O)NCCOCCOC(=O)C(Cl)O[TlH]</smiles>

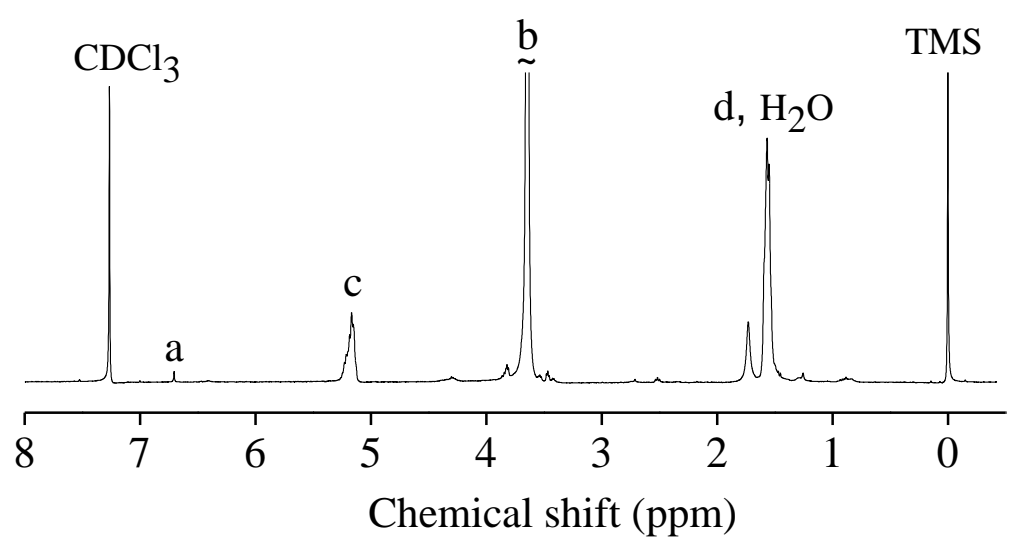

Figure S1. ${ }^{1} \mathrm{H}$ NMR spectrum $\left(\mathrm{CDCl}_{3}, 600 \mathrm{MHz}\right)$ of Mal-PEG-PDLLA. 


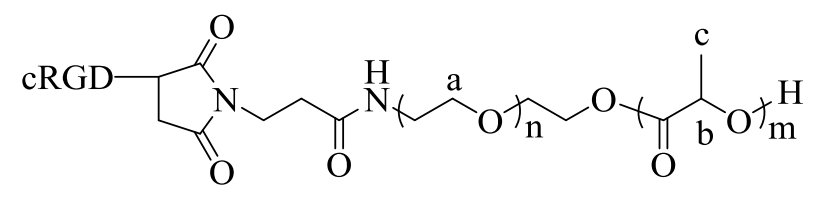

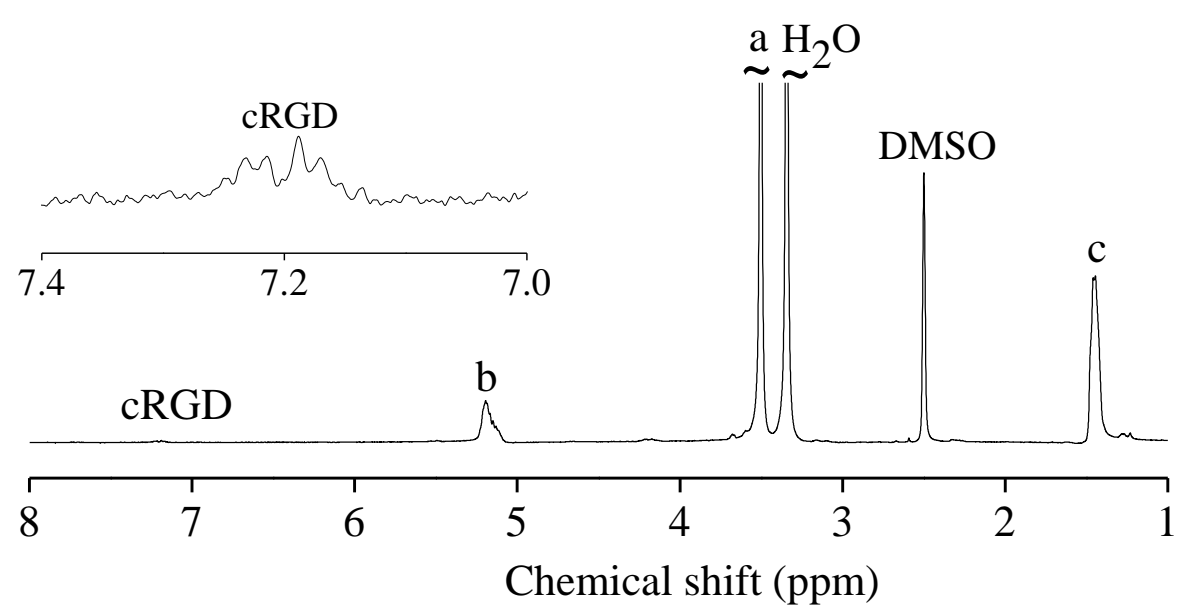

Figure S2. ${ }^{1} \mathrm{H}$ NMR spectrum (DMSO- $d_{6}, 600 \mathrm{MHz}$ ) of cRGD-PEG-PDLLA.

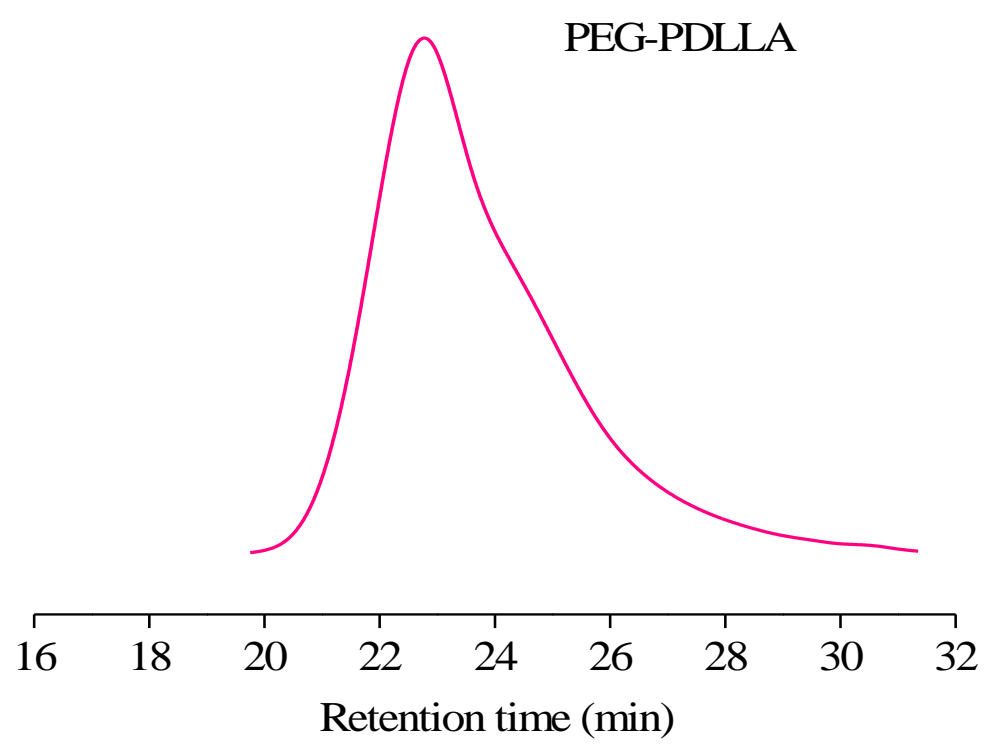

Fig. S3 GPC chromatogram of PEG-PDLLA. GPC measurement was performed using DMF containing $0.05 \mathrm{M} \mathrm{LiBr}$ as the mobile phase at a flow rate of $0.8 \mathrm{~mL} / \mathrm{min}$ at $40{ }^{\circ} \mathrm{C}$. The sample concentration was $2 \mathrm{mg} / \mathrm{mL}$. 


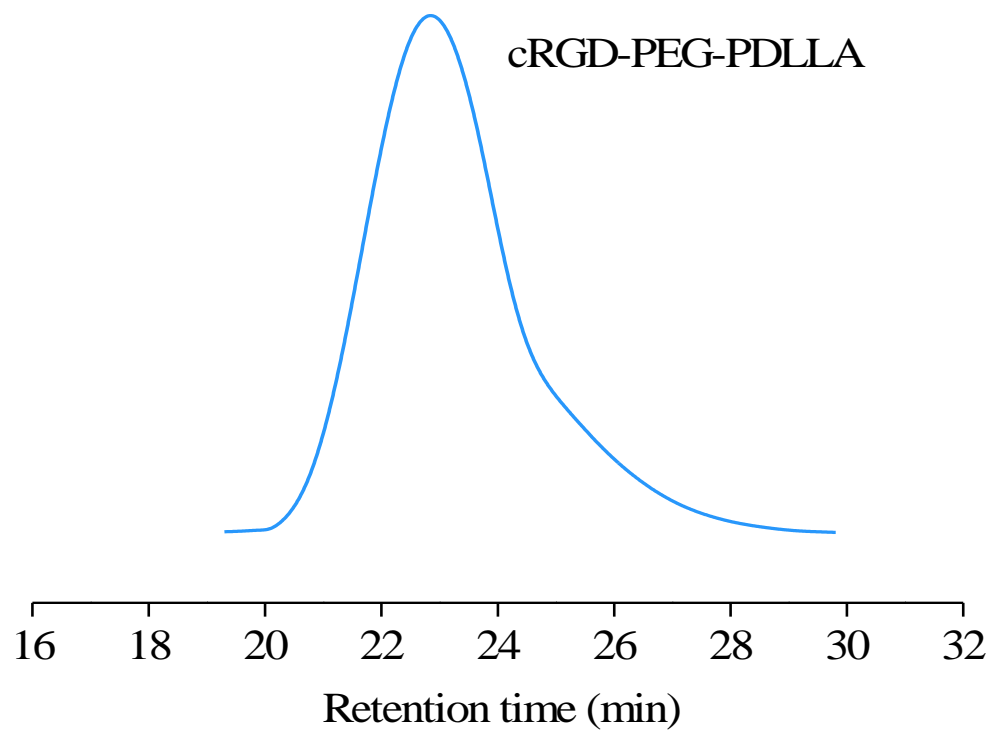

Fig. S4 GPC chromatogram of cRGD-PEG-PDLLA. GPC measurement was performed using DMF containing $0.05 \mathrm{M} \mathrm{LiBr}$ as the mobile phase at a flow rate of $0.8 \mathrm{~mL} / \mathrm{min}$ at $40{ }^{\circ} \mathrm{C}$. The sample concentration was $2 \mathrm{mg} / \mathrm{mL}$.

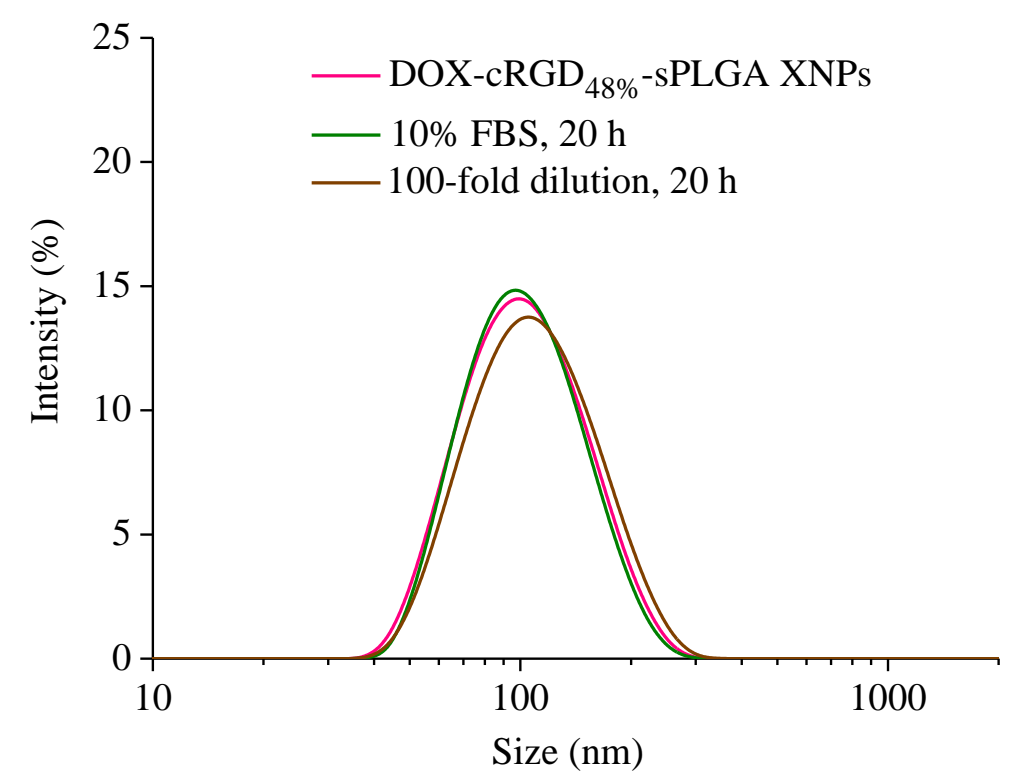

Fig. S5 Colloidal stability of DOX-cRGD $48 \%$-sPLGA XNPs against dilution and 10\% FBS.

\section{Reference}

(1) Wang, X.; Cheng, R.; Cheng, L.; Zhong, Z., Lipoyl ester terminated star PLGA as a simple and smart material for controlled drug delivery application. Biomacromolecules 2018, 19 , 1368-1373. 